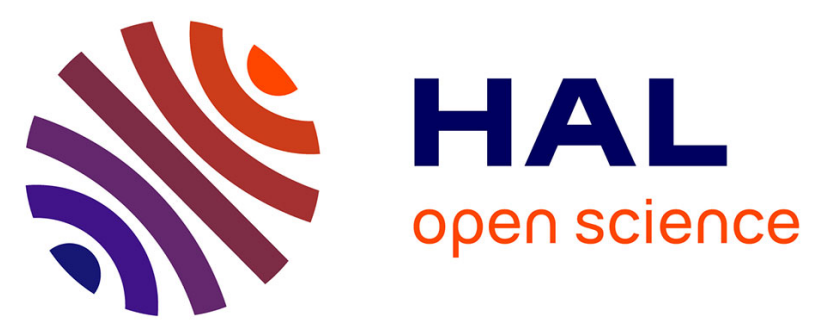

\title{
The effect of iron-chelating agents on Magnetospirillum magneticum strain AMB-1: stimulated growth and magnetosome production and improved magnetosome heating properties
}

\author{
Edouard Alphandéry, Matthieu Amor, François Guyot, Imène Chebbi
}

\section{To cite this version:}

Edouard Alphandéry, Matthieu Amor, François Guyot, Imène Chebbi. The effect of iron-chelating agents on Magnetospirillum magneticum strain AMB-1: stimulated growth and magnetosome production and improved magnetosome heating properties. Applied Microbiology and Biotechnology, 2012, 96 (3), pp.663-670. 10.1007/s00253-012-4199-5 . hal-01547086

\section{HAL Id: hal-01547086 \\ https: / hal.sorbonne-universite.fr/hal-01547086}

Submitted on 26 Jun 2017

HAL is a multi-disciplinary open access archive for the deposit and dissemination of scientific research documents, whether they are published or not. The documents may come from teaching and research institutions in France or abroad, or from public or private research centers.
L'archive ouverte pluridisciplinaire HAL, est destinée au dépôt et à la diffusion de documents scientifiques de niveau recherche, publiés ou non, émanant des établissements d'enseignement et de recherche français ou étrangers, des laboratoires publics ou privés. 
1 The effect of iron chelating agents on Magnetospirillum magneticum strain AMB-1: stimulation of growth, magnetosome production and improvement of magnetosome heating properties.

$$
\text { Edouard Alphandéry }{ }^{+, \perp,{ }^{*}, \text { Matthieu Amor }}{ }^{x+}, \text { François Guyot }^{+, x} \text { Imène Chebbi }^{\perp,} \text {, }
$$

$6 \quad+$ Institut de minéralogie et de physique des milieux condensés, UMR 7590 CNRS, Université Pierre et Marie Curie, 4 Place Jussieu, 75005, Paris, France.

${ }^{\perp}$ Nanobacterie SARL, 36 boulevard Flandrin, 75016, Paris.

9 xEquipe Géobiosphère Actuelle et Primitive, Institut de Physique du Globe de Paris, Sorbonne Paris Cité, Université Paris Diderot, UMR 7154 CNRS, 1 rue Jussieu, F-75005 Paris, France

$11 *$ *ORRESPONDING AUTHOR EMAIL ADDRESS:

12 edouardalphandery@hotmail.com 
17 The introduction of various iron chelating agents to the AMB-1 bacterial growth medium stimulates the

18 growth of AMB-1 magnetotactic bacteria and enhances the production of magnetosomes. After seven 19 days of growth, the number of bacteria and the production of magnetosomes are increased in the 20 presence of iron chelating agents by factors of up to $\sim 2$ and $\sim 6$, respectively. The presence of iron 21 chelating agents also produces an increase of the magnetosome sizes and magnetosome chain lengths 22 and yields an improvement of the magnetosome heating properties. The specific absorption rate (SAR) 23 of suspensions of chains of magnetosomes isolated from AMB-1 magnetotactic bacteria, measured 24 under the application of an alternating magnetic field of average field strength $\sim 20 \mathrm{mT}$ and frequency $25198 \mathrm{kHz}$, increases from $\sim 222 \mathrm{~W} / \mathrm{g}_{\mathrm{Fe}}$ in the absence of iron chelating agent up to $\sim 444 \mathrm{~W} / \mathrm{g}_{\mathrm{Fe}}$ in the presence of $4 \mu \mathrm{M}$ rhodamine $\mathrm{B}$ and $\sim 723 \mathrm{~W} / \mathrm{g}_{\mathrm{Fe}}$ in the presence of $4 \mu \mathrm{M}$ EDTA. These behaviors are 27 observed for an iron concentration of $20 \mu \mathrm{M}$ and iron chelating agent concentration lying below $40 \mu \mathrm{M}$.

KEYWORDS

38 Magnetosomes, magnetotactic bacteria, iron chelating agents, siderophore, magnetic hyperthermia, 39 alternating magnetic field. 
41 For a number of applications, it is advantageous to use large, single magnetic domain and wellcrystallized magnetic nanoparticles, which possess a ferrimagnetic behavior at room temperature and are not prone to aggregation (Alphandéry et al 2011). Indeed, these types of nanoparticles possess a magnetic moment, which is stronger and more stable, than that of the smaller superparamagnetic magnetic nanoparticles, usually tested in biotechnological applications. Whereas monodomain nanoparticles, which are ferrimagnetic at room temperature, can hardly be produced chemically (Borderon et al 2011), certain species of bacteria, called magnetotactic bacteria (MTB), synthesize them. The organelles made of vesicles embedding magnetic crystals are called magnetosomes. They are usually composed of magnetite in the bacteria but they can oxidize into maghemite after their extraction from the bacteria due to their contact with oxygen (Alphandéry et al 2008). In addition, the

51 magnetosomes isolated from the bacteria are not prone to aggregation due to their chain arrangement 52 and the lipidic bi-layered membrane surrounding the magnetic crystal (Alphandéry et al 2011, Komeili 53 2006). MTB use the magnetosomes as a compass to navigate in the direction of the Earth magnetic field and to presumably find with increased efficiency the optimum environment for their growth and survival (Bazylinski et al 2004). The magnetosomes have already been shown to be useful for a number of applications in the commercial, scientific or medical fields. For example, they can be used to extract DNA, to magnetically detect biomolecular interactions or to separate cells (Arakaki et al 2005). The anti-tumoral activity of a complex formed by bacterial magnetosomes and doxorubicin has also been demonstrated experimentally (Sun et al 2007). Chains of magnetosomes extracted from AMB-1 60 magnetotactic bacteria have also been shown to be efficient to eradicate tumors. For that, they have been 61 administered within tumors xeno-grafted under the skin of mice and heated under the application of an 62 alternating magnetic field. In several mice, this treatment produced the disappearance of the tumor one 63 month following the treatment (Alphandéry et al 2011). To consider a commercial application of the 64 magnetosomes, the production yield of the MTB still needs to be increased. It has recently been 65 improved in several species of magnetotactic bacteria including Magnetospirillum magneticum strain 
AMB-1 (Matsunaga et al 1990, Matsunaga et al 1996a, Matsunaga et al 1996b, Matsunaga et al 2000, Yang et al 2001a, Yang et al 2001b, Yang et al 2001b), Magnetospirillum magnetotacticum strain MS-1 (Kundu et al 2010) and Magnetospirillum gryphiswaldense strain MSR-1 (Guo et al 2011, Heyen et al 2003, Lang et al 2006, Liu et al, 2010, Sun et al, 2008). To date, the highest production yield, which has been achieved, is $55 \mathrm{mg}$ of magnetosomes synthesized per liter of growth medium and per day (Liu et al, $712010)$.

In this article, we present a method, which can be used to stimulate the growth of MTB and to improve their production yield. This method uses iron chelating agents, which are introduced to the bacterial growth medium of AMB-1 magnetotactic bacteria. A series of different iron chelating agents are tested. In addition, we also show that the introduction of iron chelating agents to the bacterial growth medium yields magnetosomes with increased magnetosome sizes and magnetosome chain lengths and results in improved magnetosome heating properties under the application of an alternating magnetic field.

\section{MATERIALS AND METHODS}

MTB belonging to the species Magnetospirillum magneticum, strain AMB-1, available at the ATCC under the reference 700264 , have been cultivated in a volume of either $10 \mathrm{ml}$ or $500 \mathrm{ml}$. A suspension containing either $100 \mu \mathrm{l}$ of $\sim 5.10^{8}$ bacteria or $5 \mathrm{ml}$ of $\sim 2.10^{9}$ bacteria was first inoculated in $10 \mathrm{ml}$ or $500 \mathrm{ml}$ of ATCC bacterial growth medium 1653 respectively. The cells were cultivated in microanaerobic conditions, $i . e$. in a culture medium that had not been degased, but that was closed and thus modified ATCC medium 1653, whose composition is given by the ATCC. The pH of the culture medium was adjusted to 6.85 by using a $5 \mathrm{M}$ solution of sodium hydroxide. The suspensions containing the various chelating agents (EDTA, ethylenediaminetetracetic acid, rhodamine B, ascorbic acid, erythrosine, anthranilic acid, citric acid, 3-(N-morpholino)propanesulfonic acid, 3-(cyclohexylamino)-1propanesulfonic acid, calcein, dextran, alendronic acid, neridronic acid, nicotinamide) mixed in water 
were then inserted within the bacterial growth medium. The concentration of iron chelating agents

91 contained within the bacterial growth medium was varied between $0.4 \mu \mathrm{M}$ and $400 \mu \mathrm{M}$.

92

93

After incubation, two different types of suspensions containing either whole inactive MTB or extracted chains of magnetosomes mixed in water were prepared. To prepare the suspensions containing the whole MTB, the cells were harvested by centrifugation at $4000 \mathrm{~g}$ during 20 minutes at room temperature. The supernate was removed and the cells were resuspended in milli-Q water. To extract the chains of magnetosomes, $2 \mathrm{ml}$ of cell suspension obtained as previously described was centrifugated again and resuspended in a $10 \mathrm{ml}$ tris- $\mathrm{HCl}$ buffer of $\mathrm{pH}$ 7.4. The cellular suspension was then sonicated during 120 minutes at $30 \mathrm{~W}$ in order to lyse the cells and collect the chains of magnetosomes. After sonication, the suspension containing the chains of magnetosomes was separated from the cellular debris by positioning a strong neodymium magnet $(0.1-1 \mathrm{~T})$ next to the tube, and the magnetic material was then harvested. The supernate containing the cellular debris and other organic molecules was eliminated. The chains of magnetosomes were washed 10 to 20 times in deionized water at $\mathrm{pH} 7.4$ and were then resuspended in $500 \mu \mathrm{L}$ of milli-Q water.

In order to obtain a sufficiently large amount of chains of magnetosomes, the MTB were first cultivated in a volume of $500 \mathrm{ml}$ either in the absence or in the presence of various chelating agents. They were centrifugated (4000 g, $20 \mathrm{~min}$ ) after 7 days of growth. The supernate was then removed and the bacteria were resuspended in $2 \mathrm{ml}$ of mili-Q-water. For the various suspensions of MTB, the absorption was measured at $565 \mathrm{~nm}$ (Heyen et al 2003) and the number of bacteria was estimated using a Beckman Coulter Z1 DT. The concentrations in maghemite of the various suspensions of extracted chains of magnetosomes were measured by absorption at $480 \mathrm{~nm}$ (Alphandéry et al 2011).

The growth curves of the MTB grown either in the absence or in the presence of the various iron chelating agents were measured for the MTB cultivated in $10 \mathrm{ml}$ elongated tubes allowing the presence of an oxygen gradient similar to that encountered in natural environments. The bacteria were centrifugated 1 day, 2 days, 3 days, 4 days, 7 days, 8 days and 9 days following the inoculation of the 
115 MTB. The supernate was removed and the bacteria were resuspended in $1 \mathrm{ml}$ of mili-Q-water. The

116 growth curves of the various suspensions of whole MTB were then measured during the ten days

117 following the inoculation by measuring both the absorption at $565 \mathrm{~nm}$ (Heyen 2003) and the number of 118 bacteria using a Beckman Coulter Z1 DT. In order to evaluate the presence (or not) of the 119 magnetosomes within the bacterial growth medium, the magnetic moments of the different suspensions 120 of magnetotactic bacteria were measured. For that, $600 \mu \mathrm{l}$ of the various suspensions of MTB were 121 deposited on top of non magnetic absorbing paper, which was then inserted within a capsule of gelatin. 122 This capsule was positioned in a SQUID. The magnetic moment of the MTB was estimated under the 123 application of a magnetic field of 1000 Oe.

124 Transmission electron microscopy (TEM) studies were carried out using a JEOL 2100F with field 125 emission gun. For the TEM measurements, $5 \mu$ of a suspension of whole MTB was deposited on top of 126 a copper grid covered with a thin amorphous carbon film. TEM measurements were used to measure the 127 sizes of the magnetosomes and to estimate the lengths of the chains of magnetosomes in bacteria 128 cultivated either in the absence or in the presence of iron chelating agents.

129 The maghemite composition of the magnetosomes was determined by measuring the saturation 130 isothermal remanent magnetization curves of the magnetotactic bacteria cultivated in various conditions 131 following the same method as that described previously (Alphandéry et al 2008). The absence of the 132 Verwey transition indicates that the magnetosomes are oxidized into maghemite.

133 The heating curves of suspensions containing $300 \mu \mathrm{l}$ of extracted chains of magnetosomes mixed in 134 water with a concentration in maghemite of $478 \mu \mathrm{g} / \mathrm{ml}$ were measured. The maghemite composition of 135 the chains of magnetosomes extracted from AMB-1 magnetotactic bacteria was estimated following a 136 method previously described (Alphandéry et al 2008). The concentration in maghemite of the different 137 suspensions of extracted chains of magnetosomes was measured at $480 \mathrm{~nm}$. To generate heat, the 138 suspensions of extracted chains of magnetosomes were exposed to an alternating magnetic field of 
frequency $198 \mathrm{kHz}$ and average field amplitude of $20 \mathrm{mT}$ using a $10 \mathrm{~kW}$ EasyHeat power supply from

140 Ambrell, Soultz, France. The average field strength within the coil was measured using a 2 D probe

141 (Suppl. Fig. 1). The temperature of the suspensions was measured using a thermocouple microprobe (IT142 18, Physitemp, Clifton, USA).

\section{RESULTS}

144 Figure 1 shows the optical absorption, measured at $565 \mathrm{~nm}$, of suspensions of MTB cultivated either in 145 the absence or in the presence of various iron chelating agents and harvested after 7 days of growth. 146 About $70 \%$ of the iron chelating agents tested produces an increase of the absorption of the suspension 147 of MTB. This indicates that in most cases the presence of iron chelating agents within the bacterial 148 growth medium stimulates the growth of the MTB. The growth stimulation is observed at low 149 concentrations of iron chelating agents, which lie below $40 \mu \mathrm{M}$ (Figure 1). The most pronounced growth 150 stimulations are observed for hemoglobin at concentration $40 \mu \mathrm{M}$, citric acid at concentration $4 \mu \mathrm{M}$, and 151 hemoglobin at concentration $4 \mu \mathrm{M}$ for which the optical absorptions of the suspension of MTB is 1.5 to 1522.5 times larger than that of the bacteria cultivated in the absence of iron chelating agents. Figure 2 153 shows the concentration in maghemite of the suspensions containing chains of magnetosomes extracted 154 from whole MTB harvested after seven days of growth and cultivated in the same conditions as those 155 presented in Figure 1. Since the magnetosomes studied here are oxidized into maghemite (Alphandéry 156 2008), the concentration in maghemite, which is measured, is equal to the concentration in 157 magnetosomes. We therefore deduce from Figure 2 that the production of magnetosomes is increased 158 for a majority of iron chelating agents tested $(\sim 65 \%)$ and for concentrations in iron chelating agents, 159 which lie below $40 \mu \mathrm{M}$. The strongest enhancement of the magnetosome production is observed when $1600.4 \mu \mathrm{M}$ or $4 \mu \mathrm{M}$ of hemoglobin is introduced within the bacterial growth medium. In this case, 161 enhancements of the magnetosome production by factors of 6 are achieved. It is also worth mentioning 162 that the concentration in iron chelating agent, which produces the largest growth stimulation, for 
example $40 \mu \mathrm{M}$ for hemoglobin (Figure 1), is not always the same as that, which yields the largest magnetosome production (for example $4 \mu \mathrm{M}$ for hemoglobin).

165
The influence of introducing iron chelating agents to the bacteria growth medium on several MTB and magnetosome properties is studied next. We describe the results obtained with an iron chelating agent, rhodamine $\mathrm{B}$, which shows a typical behavior, $i$. e. which stimulates well both the growth of the MTB and the production of the magnetosomes. Figure 3(a) shows the growth curves of MTB cultivated either in the absence of rhodamine $\mathrm{B}$ or in the presence of different concentrations of rhodamine $\mathrm{B}$. In the presence of $0.4 \mu \mathrm{M}, 4 \mu \mathrm{M}$ or $40 \mu \mathrm{M}$ of rhodamine B introduced to the bacterial growth medium, the growth of MTB is more rapid than in the absence of rhodamine B. The concentration of $400 \mu \mathrm{M}$ of rhodamine B does not stimulate the growth of MTB. The growth stimulation induced by the presence of rhodamine $\mathrm{B}$ is significant during the 3 or 4 first days of growth, i. e. during the exponential phase. After that, the bacteria reach the stationary phase and then the absorption of the different suspensions of bacteria decreases most probably due to the death of the bacteria (Suppl. Fig. 2). In order to determine the rate at which the magnetosomes grow, the magnetic moments of the suspensions of MTB cultivated in the absence or in the presence of various concentrations of rhodamine B were measured for an applied magnetic field of 1000 Oe. Before the fourth day of growth, the magnetic moments of the various suspensions of bacteria were not detected indicating the absence or undetectable concentrations of magnetosomes in these suspensions. At days 4, 7 and 8, the magnetic moments of the suspensions containing MTB cultivated in the presence of $0.4 \mu \mathrm{M}, 4 \mu \mathrm{M}$ or $40 \mu \mathrm{M}$ of rhodamine B were detected. The magnetic moments of the suspensions containing MTB cultivated in the absence of rhodamine B were detected at a later stage during the ninth day of growth, indicating that the production of the magnetosomes is more rapid for the MTB cultivated in the presence of rhodamine B than for those cultivated in the absence of rhodamine B. The stimulations of the growth of the bacteria and of the production of the magnetosomes were observed for other iron chelating agents introduced within the bacterial growth medium, such as ascorbic acid (Suppl. Fig. 3). 
The magnetosome sizes and magnetosome chain lengths of the extracted chains of magnetosomes were measured for the MTB cultivated in the absence of rhodamine B and for those cultivated in the presence of $4 \mu \mathrm{M}$ of rhodamine B (Figure 4). The distributions in magnetosome sizes and magnetosome chain lengths are bimodal. For the magnetosomes of small sizes, the magnetosome sizes and magnetosome chain lengths increase from an average of $\sim 27.5 \mathrm{~nm}$ and $\sim 150 \mathrm{~nm}$ in the absence of iron chelating agent up to an average of $\sim 35 \mathrm{~nm}$ and $\sim 200 \mathrm{~nm}$ in the presence of $4 \mu \mathrm{M}$ rhodamine $\mathrm{B}$, respectively (Figures 4(a)-(d)). The largest magnetosomes of the longest chains increase from an average of $\sim 42.5 \mathrm{~nm}$ and $750 \mathrm{~nm}$ in the absence of rhodamine $\mathrm{B}$ up to an average of $\sim 65 \mathrm{~nm}$ and $\sim 800$ in the presence of rhodamine B, respectively (Figures 4(a)-(d)). The increase of the magnetosome sizes and magnetosome chain lengths was also observed in the presence of other iron chelating agents such as EDTA (Suppl. Fig. 4).

Three suspensions containing $300 \mu \mathrm{l}$ of extracted chains of magnetosomes with a concentration in maghemite of $478 \mu \mathrm{g} / \mathrm{ml}$ were then heated under the application of an alternating magnetic field of frequency $198 \mathrm{kHz}$ and average magnetic field strength of $20 \mathrm{mT}$. These suspensions contain chains of magnetosomes synthesized either in the absence or in the presence of $4 \mu \mathrm{M}$ Rhodamine $\mathrm{B}$ or $4 \mu \mathrm{M}$ EDTA. Figure 5(a) shows that the absorption curves of the three suspensions are the same, indicating that their concentration is identical. The variations of temperature as a function of time of the three suspensions are shown in Figure 5(b). The increase in temperature is more important in the presence of $4 \mu \mathrm{M}$ rhodamine $\mathrm{B}$ or $4 \mu \mathrm{M}$ EDTA than in the absence of iron chelating agent. The slopes, measured at $25{ }^{\circ} \mathrm{C}$, of the variations of temperature with time shown in Figure $5(\mathrm{~b})$, designated as $\Delta \mathrm{T} / \delta \mathrm{t}$, increase from $\Delta \mathrm{T} / \delta \mathrm{t} \sim 0.005{ }^{\circ} \mathrm{C} / \mathrm{sec}$. in the absence of iron chelating agent up to $\Delta \mathrm{T} / \delta \mathrm{t} \sim 0.011{ }^{\circ} \mathrm{C} / \mathrm{sec}$ in the presence of $4 \mu \mathrm{M}$ Rhodamine and $0.017^{\circ} \mathrm{C} / \mathrm{sec}$ in the presence of $4 \mu \mathrm{M}$ EDTA. Using the relation between the specific absorption rate $(\mathrm{SAR})$ and $(\Delta \mathrm{T} / \delta \mathrm{t})$, which is given by $\mathrm{SAR}=\mathrm{C}_{\mathrm{v}}(\Delta \mathrm{T} / \delta \mathrm{t})$, where $\mathrm{C}_{\mathrm{v}}=$ 4.2 J/(g.K) is the specific heat capacity of water, we find that the $\mathrm{SAR}$ increases from $\sim 222 \mathrm{~W} / \mathrm{g}_{\mathrm{Fe}}$ in the 
212 absence of iron chelating agent up to $\sim 444 \mathrm{~W} / \mathrm{g}_{\mathrm{Fe}}$ in the presence of $4 \mu \mathrm{M}$ rhodamine $\mathrm{B}$ and $\sim 723$

$213 \mathrm{~W} / \mathrm{gFe}$ in the presence of $4 \mu \mathrm{M}$ EDTA.

\section{DISCUSSION}

215 We have shown that the presence of iron chelating agents within the bacterial growth medium stimulates

216 the production of the magnetosomes. The function of the iron chelating agents is to chelate $\mathrm{Fe}^{3+}$ iron

217 ions and to enhance the bioavailability of iron by forming $\mathrm{Fe}^{3+}$-ligand complexes. The iron chelating 218 agents could be involved in one or several of the following steps of the magnetosome formation, (i) the

219 formation of the vesicle in which the magnetosomes are formed, (ii) the iron uptake by the cells, (iii) the 220 iron transport within the cells and (iv) the control of the biomineralization of the magnetosome 221 formation in $\mathrm{Fe}_{3} \mathrm{O}_{4}$ or $\gamma \mathrm{Fe}_{2} \mathrm{O}_{3}$ (Bazylinski 2004). They could therefore favor the magnetosome formation 222 by making each or several of these steps more efficient.

223 We examine why the presence of iron chelating agents stimulates the growth of the bacteria. The 224 mechanisms, which enhance the production of the magnetosomes and those, which stimulate the growth 225 of the bacteria, are expected to be different. The MTB are believed to synthesize siderophores, which 226 help to incorporate iron within the bacteria (Calugay 2006). In the absence of such complexing agents, $227 \mathrm{Fe}^{3+}$ iron ions precipitate mostly as ferrihydrite and their bioavailability is likely strongly decreased. 228 When iron chelating agents are introduced to the bacterial growth medium, the MTB have less need to 229 synthesize siderophores. It is thus likely that the energy allocated for siderophore synthesis can then be 230 used for bacterial growth. This could explain the more efficient growth observed in the presence than in 231 the absence of iron chelating agents.

232 We also observe that the highest stimulation of the bacteria is observed for large iron chelating agents, 233 such as hemoglobin. This result suggests that iron is chelated in a more efficient way using high 234 molecular weight than low molecular weight iron chelating agents. This is in agreement with previous 235 study (Reichard et al, 2007). There are several possible explanations for this behavior. The stability 
formed by a large iron complex could be higher than that formed by a smaller iron complex. A large iron

complex may also more easily enter within the periplasm of the cells. It is also possible that a large iron complex would more easily release iron within the bacterial cells or that it would favor oxidoreduction reactions involved in the magnetosome production or crystallization process.

We have shown that above a concentration in iron chelating agent lying between $40 \mu \mathrm{M}$ and $400 \mu \mathrm{M}$,

241 the stimulation of the growth of the MTB and of the production of the magnetosomes is not observed.

242 This result agrees with previous reports, which showed that for a ratio of 100 to 500 between the iron 243 chelating agent and iron concentrations, no growth stimulation was observed for the species MSR-1 244 (Schüler 1996). This indicates that the iron chelating agents are toxic above concentrations lying 245 between $40 \mu \mathrm{M}$ and $400 \mu \mathrm{M}$. We propose two hypotheses to explain this result. Either a high iron 246 chelating agent concentration yields a high iron concentration within the bacterial growth medium, 247 which is toxic for the magnetotactic bacteria. Or the reactive oxygen species, which are formed because 248 of the alcohol functional groups getting unbound from iron, for example in rhodamine B, damage the 249 membrane of the bacteria.

250 The kinetics of the magnetosome formation is reported for the AMB-1 species. For this species, the 251 magnetosomes are probably mainly formed after the magnetotactic bacteria have reached the stationary 252 phase (Yang 2001). We have shown that the introduction of iron chelating agents within the bacterial 253 growth medium of AMB-1 magnetotactic bacteria yields faster growth of magnetosomes. This should 254 therefore enable a significant increase in the rate of production of the magnetosomes by the AMB-1 255 magnetotactic bacteria. In strain MSR-1, the magnetosomes are produced earlier, before the bacteria 256 have reached the stationary phase (Heyen and Schüler 2003). This behavior could be explained by a 257 different mechanism of iron uptake or of magnetosome formation between these two species of 258 magnetotactic bacteria. Therefore, the influence of introducing iron chelating agents within the bacterial 259 growth medium on growth rate of magnetosome production may be less pronounced for the MSR-1 than 260 for the AMB-1 species. 
261 The introduction of iron chelating agents to the bacterial growth medium also increases the 262 magnetosome sizes and magnetosome chain lengths, which results in an improvement of the 263 magnetosome heating properties. The specific absorption rate of suspensions of extracted chains of 264 magnetosomes increases by a factor of 3 between the MTB cultivated in the absence of iron chelating 265 agent and those cultivated in the presence of $4 \mu \mathrm{M}$ EDTA. High values of SAR are advantageous to 266 carry out magnetic hyperthermia treatments of cancers since they enable the use of a small quantity of 267 magnetosomes and/or the application of an alternating magnetic field of low strength, hence decreasing 268 the risks of toxicity.

269 Further studies should explore separately the effect of iron on either the bacterial growth or the 270 production of magnetosomes.

271 In conclusion, the introduction of iron chelating agents within the bacterial growth medium enables the 272 stimulation of the growth of the MTB, the enhancement of the production yield of the magnetosomes, 273 the increase of the magnetosome sizes and magnetosome chain lengths as well as the enhancement of 274 the magnetosome heating properties under the application of an alternating magnetic field.

\section{ACKNOWLEDGMENTS}

276 F. Guyot and M. Amor do not claim any inventive contribution in this work. They only analyzed 277 experimental results.

\section{REFERENCES}

279 Alphandéry E, Faure S, Seksek O, Guyot F, Chebbi I (2011) Chains of magnetosomes extracted from $280 A M B-1$ magnetotactic bacteria for application in alternative magnetic field cancer therapy 5:6279-6296.

281 Alphandéry E, Ngo A T, Lefèvre C, Lisiecki I, Wu L F, Pileni M P (2008) Difference between the 282 Magnetic Properties of the Magnetotactic Bacteria and Those of the Extracted Magnetosomes: Influence 283 of the Distance between the Chains of Magnetosomes J. Phys. Chem. 112:12304-12309. 
284 Arakaki A, Nakazawa H, Nemoto M, Mori T, Matsunaga T (2008) Formation of magnetite by bacteria 285 and its application J. R. Soc. Interface 5:977-999.

286 Bazylinski DA, Frankel RB (2004) Magnetosome formation in prokaryotes Nature Reviews 287 Microbiology 2:217-230.

288 Bordelon DE, Cornejo C, Grüttner C, Westphal F, DeWeese TL, Ivkov R (2011) Magnetic nanoparticle 289 heating efficiency reveals magneto-structural differences when characterized with wide ranging and high 290 amplitude alternating magnetic fields J. Appl. Phys. 109:124904-124904-8.

291 Calugay RJ, Miyashita H, Okamura Y, Matsunaga T (2008) Siderophore production by the magnetic 292 bacterium Magnetospirillum magneticum $A M B-1$ FEMS Micribiology Letters 218:371-375.

293 Guo F, Liu Y, Chen Y, Tang T, Jiang W, Li Y, Li J (2011) A novel rapid and continuous procedure for 294 large-scale purification of magnetosomes from Magnetospirillum gryphiswaldense Appl. Microbiol. 295 Biotechnol. 90:1277-1283.

296 Heyen U, Schüler D (2003) Growth and magnetosome formation by microaerophilic Magnetospirillum 297 strains in an oxygen-controlled fermentor (2003) Appl. Microbiol. Biotechnol. 61:536-544.

298 Komeili A (2006) Cell biology of magnetosome formation Microbiol. Monogr. 3:163-174.

299 Kundu S, Kulkarni GR (2010) Enhancement of magnetotactic bacterial yield in a modified MSGM 300 medium without alteration of magnetosomes properties Indian J. Exp. Bio. 48:518-523.

301 Lang C, Schüler D (2006) Biogenic nanoparticles: production, characterization, and application of 302 bacterial magnetosomes J. Phys. Condens. Matter 18:S2815-S2828.

303 Liu Y, Li GR, Guo F, Jiang W, Li Y, Li LJ (2010) Large-scale production of magnetosomes by 304 chemostat culture of Magnetospirillum gryphiswaldense at high cell density Microbial Cell Factories 305 9:99. 
306 Matsunaga T, Tadokoro F, Nakamura N (1990) Mass culture of magnetic bacteria and their application

307 to flow type immunoassays IEE Trans. Mag. 26:1557-1559.

308 Matsunaga T, Kawasaki M, Yu X, Tsujimura N, Nakamura N (1996) Chemiluminescence Enzyme 309 Immunoassay Using Bacterial Magnetic Particles Anal. Chem. 68:3551-3554.

310 Matsunaga T, Tsujimura N, Kamiya S (1996) Enhancement of magnetic particle production by nitrate 311 and succinate fed-batch culture of Magnetospirillum sp. AMB-1 Biotechnology Techniques 10:495-500.

312 Matsunaga T, Togo H, Tanaka T (2000) Production of Luciferase-Magnetic Particle Complex by 313 Recombinant Magnetospirillum sp. AMB-1 Biotechnology and bioengineering 70:704-709.

314 Reichard P U, Kretzschmar R, Kraemer S M (2007) Dissolution mechanisms of goethite in the presence 315 of siderophores and organic acids Geochimica et Cosmochimica Acta. 71:5635-5650.

316 Schüler D, Bauerlein E (1996) Iron-limited growth and kinetics of iron uptake in Magnetospirillum 317 gryphiswaldense Arch. Microbiol. 166:301-307

318 Sun JB, Zhao F, Tang T, Jiang W, Tian JS, Li Y, Li JL (2008) High-yield growth and magnetosome 319 formation by Magnetospirillum gryphiswaldense MSR-1 in an oxygen-controlled fermentor supplied 320 solely with air Appl. Microbiol. Biotechnol. 79:389-397.

321 Sun JB, Duan JH, Dai SL, Ren J, Zhang YD Tim JS Li Y (2007) In vitro and in vivo antitumor effects 322 of doxorubicin loaded with bacterial magnetosomes (DBMS) on H22 cells: The magnetic bio323 nanoparticles as drug carriers Cancer Letters 258:109-117.

324 Yang CD, Takeyama H, Tanaka T, Hasegawa A, Matsunaga T (2001) Synthesis of Bacterial Magnetic 325 Particles During Cell Cycle of Magnetospirillum magneticum AMB-1 Appl. Biochem. Biotech. 91:155326160. 
327 Yang CD, Takeyama H, Tanaka T, Matsunaga T (2001a) Effects of growth medium composition, iron 328 sources and atmospheric oxygen concentrations on production of luciferase-bacterial magnetic particle 329 complex by a recombinant Magnetospirillum magneticum AMB-1 Enz. Microb. Tech. 29:13-19.

330 Yang C, Takeyama H, Matsunaga T (2001b) Iron Feeding Optimization and Plasmid Stability in 331 Production of Recombinant Bacterial Magnetic Particles by Magnetospirillum magneticum AMB-1 in 332 Fed-Batch Culture J. Bioscience Bioeng. 2:231-216.

333

334

335

336

337

338

339

340

341

342

343

344

345

346 


\section{FIGURES}

348 Figure 1: Absorption measured at $565 \mathrm{~nm}$ and number of magnetotactic bacteria per ml of suspensions

349 of magnetotactic bacteria cultivated either in the absence of iron chelating agents or in the presence of $3500.4 \mu \mathrm{M}, 4 \mu \mathrm{M}, 40 \mu \mathrm{M}$ or $400 \mu \mathrm{M}$ of various iron chelating agents. These chelating agents are EDTA, 351 rhodamine B, ascorbic acid, erythrosine, anthranilic acid, citric acid, 3-(N-morpholino)propanesulfonic 352 acid, 3-(cyclohexylamino)-1-propanesulfonic acid, calcein, dextran, alendronic acic, neridronic acid and 353 nicotinamide. Dotted lines represent control values.

354 Figure 2: The concentration in maghemite of suspensions containing chains of magnetosomes extracted 355 from whole magnetotactic bacteria. The magnetotactic bacteria have been cultivated either in the 356 absence or in the presence of the same iron chelating agents as in Figure 1.

357 Figure 3: (a) The growth curves of magnetotactic bacteria cultivated either in the absence of rhodamine 358 B or in the presence of $0.4 \mu \mathrm{M}, 4 \mu \mathrm{M}, 40 \mu \mathrm{M}$ or $400 \mu \mathrm{M}$ of rhodamine $\mathrm{B}$. The growth curves represent 359 the absorption of the different suspensions of magnetotactic bacteria at $565 \mathrm{~nm}$ (left y scale) or the 360 number of MTB per ml (right y scale) measured at the different days of growth (day 0, day 1, day 3, day 361 4). (b) The Magnetic moments of the suspensions of magnetotactic bacteria cultivated either in the 362 absence or in the presence of $0.4 \mu \mathrm{M}, 4 \mu \mathrm{M}, 40 \mu \mathrm{M}$ or $400 \mu \mathrm{M}$ of rhodamine $\mathrm{B}$, measured under the 363 application of a magnetic field of 1000 Oe during the fourth day, the seventh day, the eighth day or the 364 ninth day of bacterial growth.

365 Figure 4: (a), (b) The magnetosome size distribution of the magnetosomes contained within the 366 magnetotactic bacteria for the bacteria cultivated either in the absence, (a), or in the presence of $4 \mu \mathrm{M}$ 367 rhodamine B, (b). (c), (d) The magnetosome chain length distribution of the chains of magnetosomes 368 contained within the magnetotactic bacteria for the bacteria cultivated either in the absence, (c), or in the 369 presence of $4 \mu \mathrm{M}$ rhodamine $\mathrm{B},(\mathrm{d})$. 
370 Figure 5: (a) The absorption curves of three suspensions of extracted chains of magnetosomes. The

371 MTB were cultivated either in the absence of iron chelating agent, in the presence of $4 \mu \mathrm{M}$ rhodamine $\mathrm{B}$ 372 or in presence of $4 \mu \mathrm{M}$ EDTA. (b) The variations of temperature as a function of time of the same 373 suspensions as in (a) exposed to an alternating magnetic field of frequency $198 \mathrm{kHz}$ and average field 374 strength of $20 \mathrm{mT}$. Ch-Std, Ch-EDTA $(4 \mu \mathrm{M})$ and Ch-Rhodamine B $(4 \mu \mathrm{M})$ designate the chains of 375 magnetosomes isolated from the bacteria obtained by cultivating the bacteria in the absence of iron 376 chelating agent, in the presence of $4 \mu \mathrm{M}$ EDTA or in the presence of $4 \mu \mathrm{M}$ rhodamine $\mathrm{B}$, respectively. 


\section{Whole magnetotactic bacteria AMB-1 harvested after 7 days of growth}

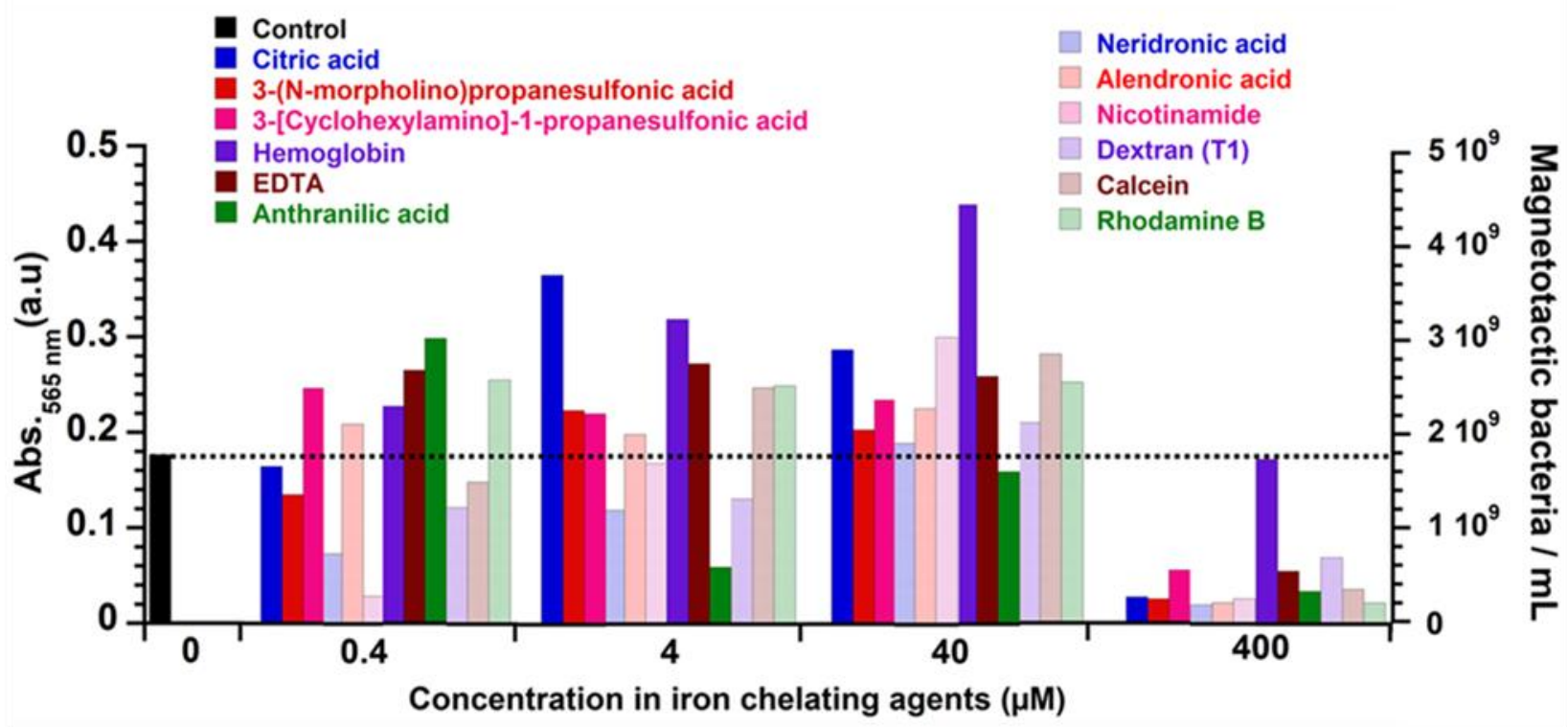

FIG. 1

386

387

388

389

390

391

392

393 


\section{Extracted chains of magnetosomes}

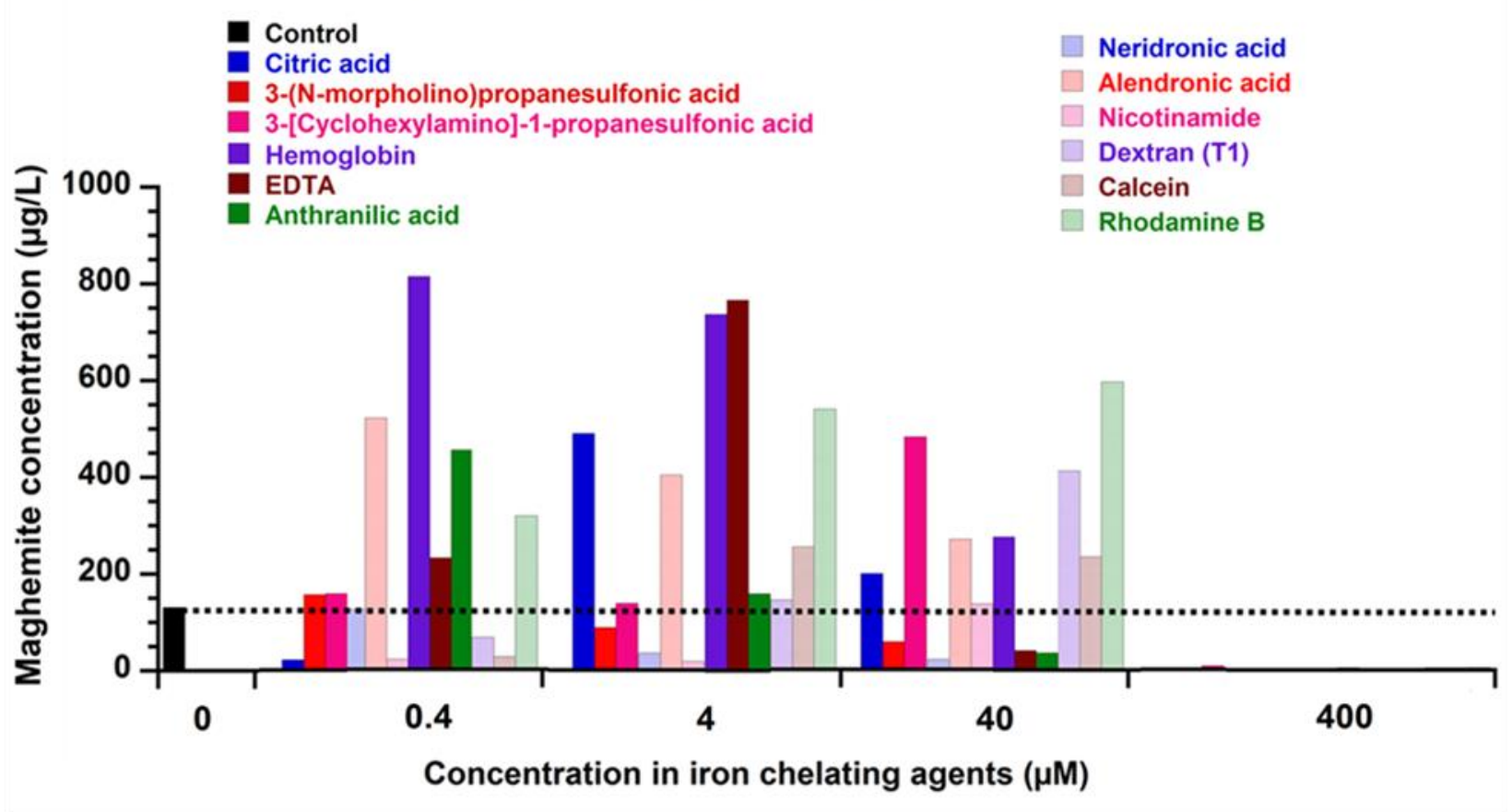

399

FIG. 2

400

401

402

403

404

405

406

407

408

409 


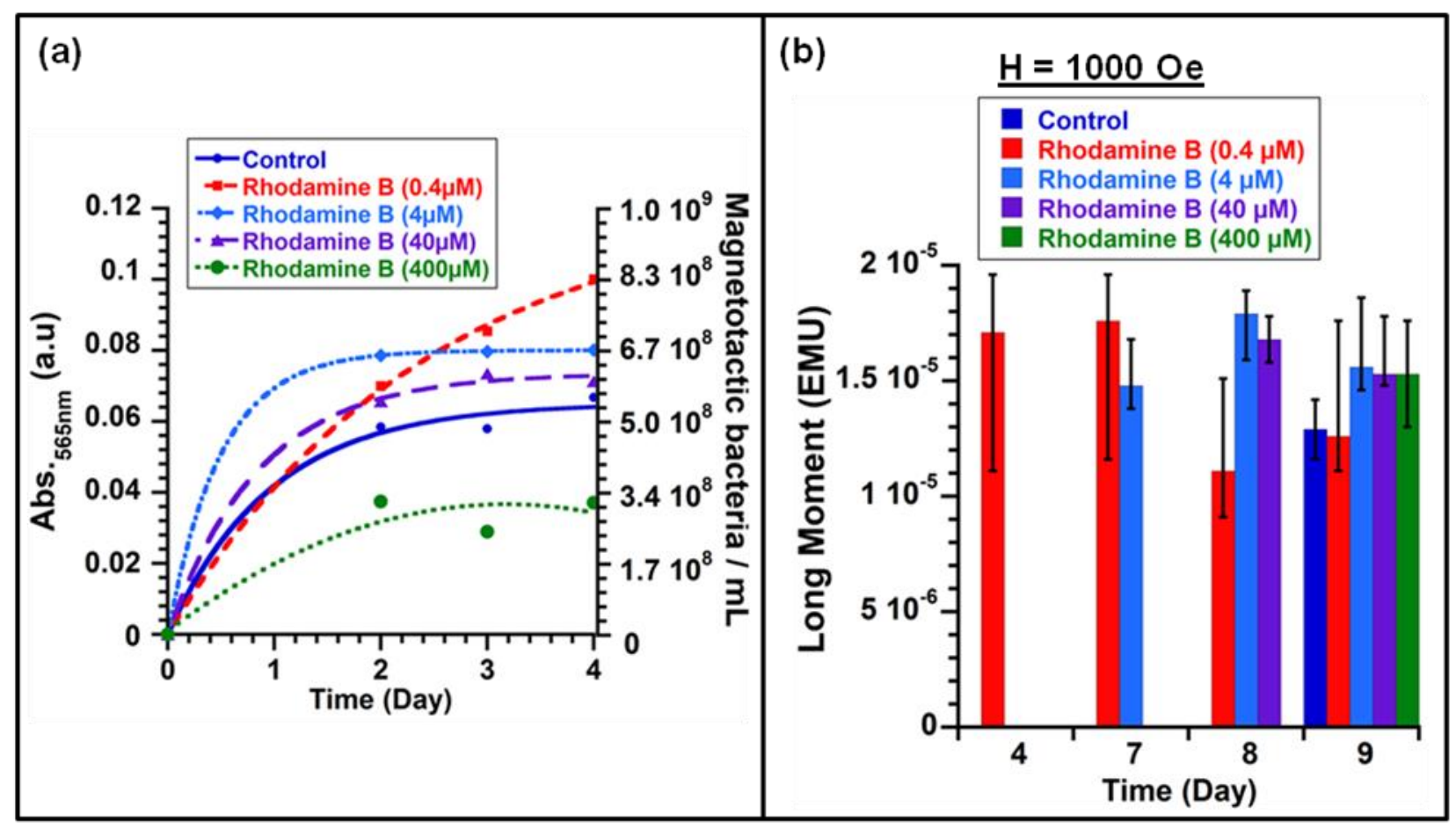

410

FIG. 3

411

412

413

414

415

416

417

418

419

420

421 


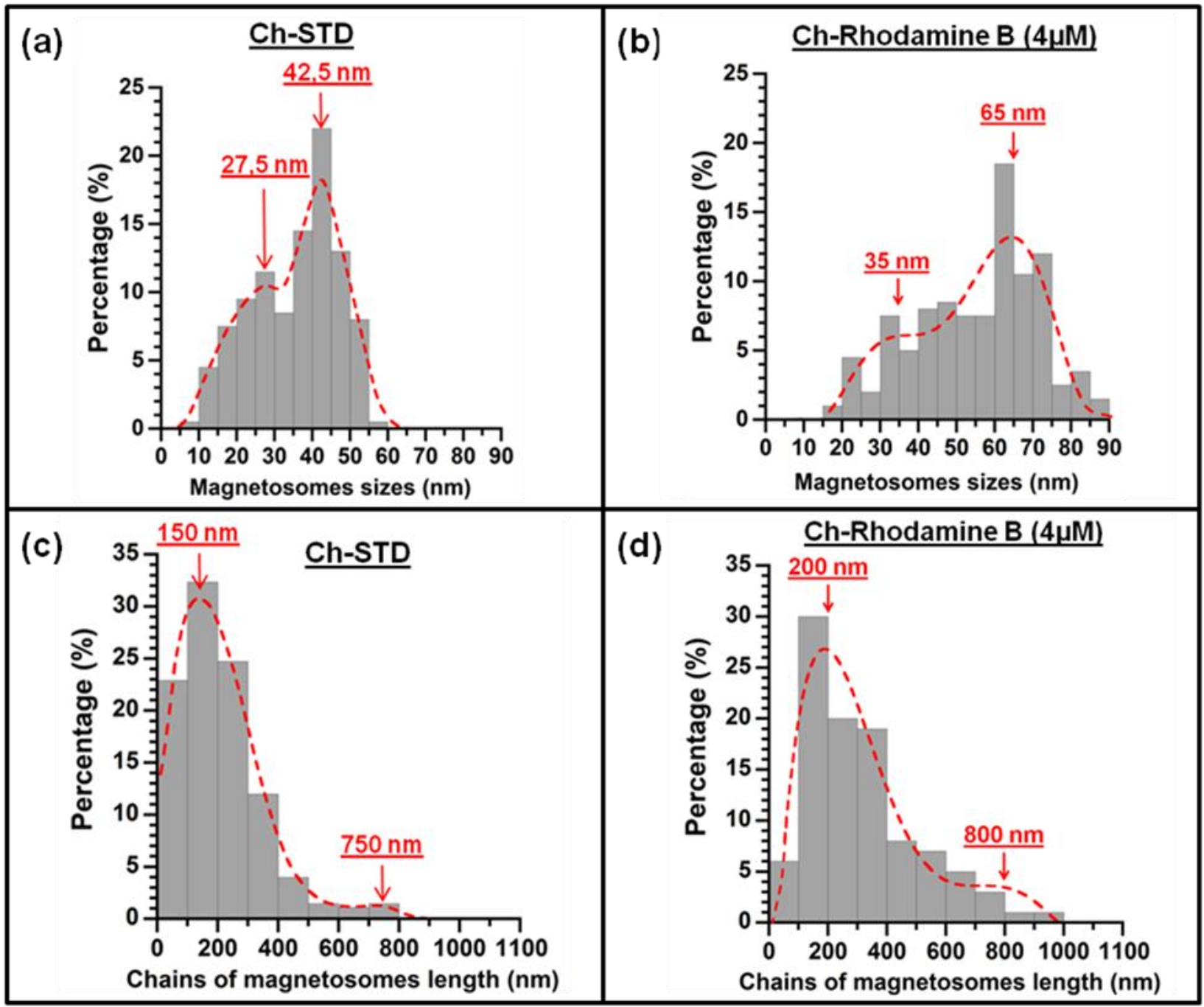

FIG. 4 


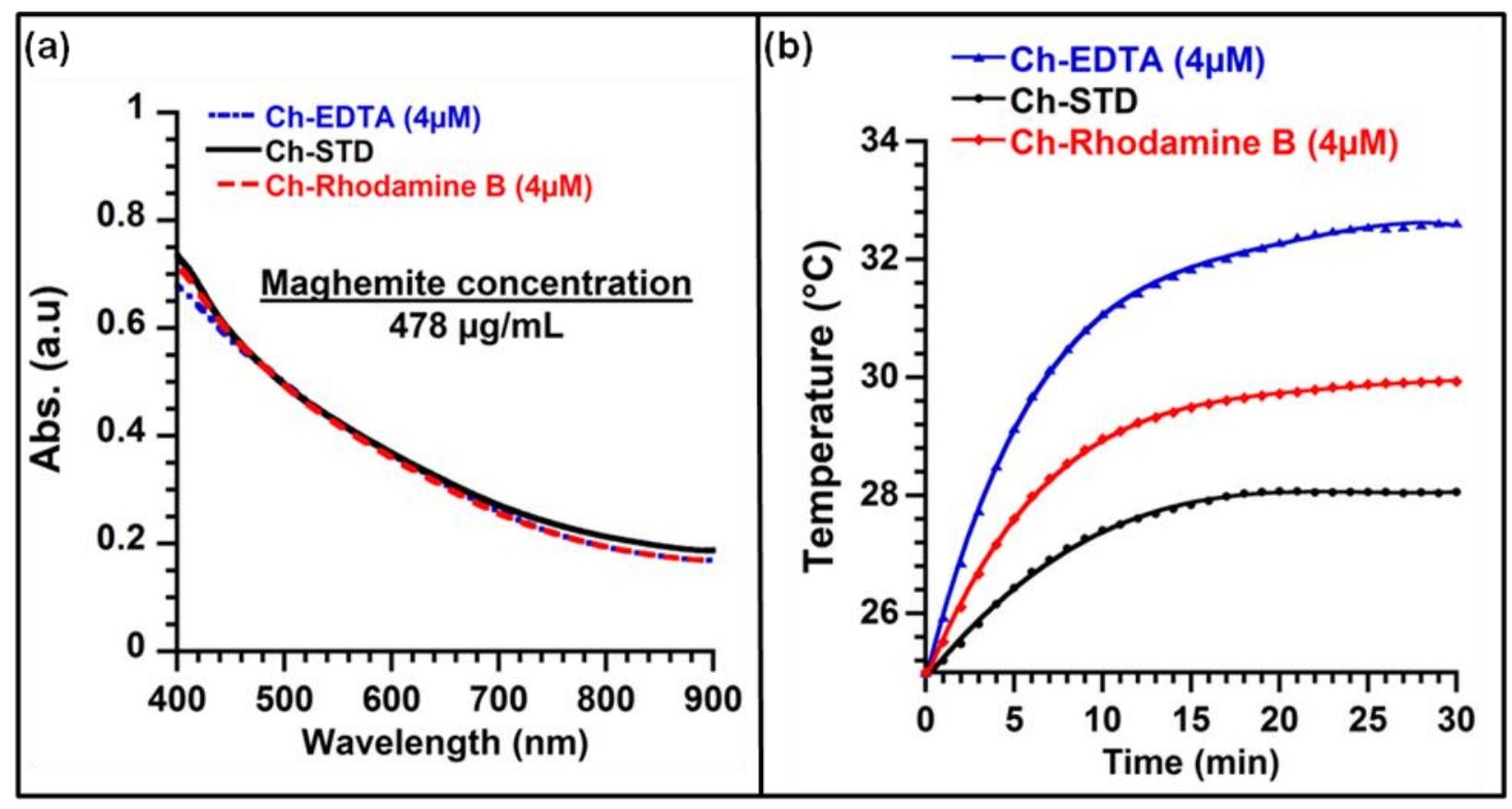

FIG. 5 